\title{
Determinants of Performance Management Practices: A Case Study of National Bank of Pakistan
}

\author{
Ayesha Yaseen (Corresponding Author) \\ MS Scholar, Department of Management Sciences, The Islamia University of Bahawalpur \\ Email: Ayesha_ayesha12@hotmail.com
}

Sehrish Afghan

Department of Management Sciences, The Islamia University of Bahawalpur

Email: sehrishafghan@hotmail.com

Received: February 03, 2016 Accepted: February 25, 2016 Published: February 28, 2016

doi:10.5296/ijhrs.v6i1.9113 URL: http://dx.doi.org/10.5296/ijhrs.v6i1.9113

\begin{abstract}
There is drive and momentum to implement changes in the public sector organizations and for such changes it is first and foremost dilemma to analyze the performance management system and practices implemented in such organizations. This study explores the performance management system at National bank of Pakistan. It's a descriptive study and main focus of this study is to identify the flaws in performance management system that are currently prevailing at National bank of Pakistan and suggesting new ideas to bring positive changes ultimately getting competitive advantage through Human Resource Management (HRM). For analyzing the study, a sample of 100 employees has been selected on convenient basis form Bahawalpur Region and reposes are obtained on the fully structured questionnaires and analyze the results through Chi-Square technique.
\end{abstract}

Keywords: Performance management system, reward, motivation, feedback and performance criterion 


\section{$\Lambda$ Macrothink}

\section{Introduction}

\subsection{Background of Study}

Although the term measurement of performance in the public sector is quite new and major work on that area is extracted from literature of late 1970s encompassing terms such as performance measures, performance indicators, performance appraisal and review, value for money and, more recently, quality assurance. This literature has mirrored a parallel development in which the language of performance has become an almost every day feature of work in public sector organizations, in some form or another. Similarly, a new "industry" has developed within the public sector which is concerned with collecting, reporting, and appraising organizational performance.

Nowadays, organizations are giving so much importance to efficient performance and struggling hard to remain competitive. Performance management focuses on the achievement of goals effectively and efficiently it focuses mainly on the Organization, specific department and employees performances. One of the crucial functions of an organization is to manage human resources effectively. Nowadays, due to globalization, economic pressures and competition financial institutions are trying harder to manage their costs and customer relations in order to maintain competitive advantage. Main focus of this study is National Bank of Pakistan because it's a leading bank. The nature of responsibilities of the National Bank is different and unique from other banks/financial institutions. The Bank acts as the agent to the State Bank of Pakistan for handling Provincial/Federal Government Receipts and Payments on their behalf. The Bank has also played an important role in financing the country's growing trade, which has expanded through the years as diversification took place. These factors are provoking banks to give importance to their performance management system.

\subsection{Aim Of The Study}

The aim of this study is to analyze the prevailing performance management practices and techniques that are used by National Bank of Pakistan and what are the determinants of the performance appraisal of employees. The current study has broad view to see the effects of current performance management practices on employees' performance and as well as on the overall performance of National Bank of Pakistan, then compare these practices with other performance management practices and suggesting the corrective measures to make it more effective in terms of employee satisfaction and to remain National Bank of Pakistan competitive in the current dynamic banking industry in Pakistan and internationally as well.

\subsection{Research Question}

Specifically the study would answer the question:

- What are the determinants of performance management practices and what are the factors that affect performance management practices? 


\section{Ml Macrothink}

International Journal of Human Resource Studies

ISSN 2162-3058 2016, Vol. 6, No. 1

The study would attempt to prove the potential link between performance management practices, systems, employees' performance and organizational competitiveness, so that National Bank of Pakistan can improve employees' performance and competitive in the banking industry through effective utilization of good performance management practices.

\subsection{Research Objectives}

This study seeks to examine:

- The determinants of performance evaluation and practices among the servicing organizations.

- The performance management practices carried out by the financial sector of Pakistan.

- Factors influencing the performance management practices in National bank of Pakistan.

- Suggesting policy recommendations for improving performance management and evaluation in National bank of Pakistan.

\subsection{Delimitation Of The Study}

The study would be conducted on the National Bank of Pakistan and limits to Bahawalpur region that will restrict it's generalize ability on the other sectors of economy and study also limit to employees at managerial positions at Bahawalpur region and exclude non-managerial employees.

\section{Literature Review}

Financial institutions are struggling hard in order to create a competitive edge by Human Resource management. National Bank of Pakistan is today a progressive, efficient, and customer focused institution. It has developed a wide range of consumer products, to enhance business and cater to the different segments of society. Now they have realized the importance of competent workforce and working hard to manage, motivate and retain them. Performance of an organization depends upon the performance of its employees. In order to increase the employee's performance banks need to focus and design a systematic performance management system.

Performance management is a long term, multidimensional and ongoing process. Performance management starts when an employee's job is defined and ends when he leaves the organization. Performance management is about clarifying employees about their job duties, defining employees the performance standards by mutual understanding, documenting, evaluating them and giving feedback to all the employees.

\subsection{Definition}

Performance management is a process of getting favorable outcomes according to the strategic goals of an organization; it involves a lot of activities that enhance the performance of employees accordingly. The performance management improves employee performance at 
work. Furthermore, it develops their skills personally and as a whole in a group in order to maintain success of an organization, it is basically a long term and inter-linked system (Michael Armstrong, 1998). Performance management is an integral part of the managers and employees job. It is a joint process. Its main focus is on the key issues and business objectives. It is much more than telling people what to do. PMS gives the clear idea about what is being expected in a particular role. This reduces uncertainty, ambiguity, frustration, burnouts and ineffectiveness and uplift employees' motivation. This imparts positive and long term effect on the sustainability of an organization. Performance management is different and much broader from performance appraisal as performance management includes development of employees, managing performance of employees and performance appraisal. It is an integrated process. Management by agreement and targeted towards individual growth and qualitative aspect like training and development and long terms benefits. It is the process in which employees are being guided and supported to perform a work accurately and proficiently according to the goals and requirements of the organization (Walters, 1995).Performance management is an on-going process that identifies measure and develops performance of employees and the organization in accordance with strategic goals (Aguinis, 2007).

\subsection{Meaning of performance}

Performance is defined as Behaviors and Results (Brumbach, 1988)Performance management system includes behaviors and results. Behavior in terms of how the task or goals are achieved. What employees are doing or do. Behaviors are not always measurable and observable so results can be used as proxy for behavioral measure. There are different kinds of behaviors that advance or hinder organizational goals (Boland \& Fowler, 2000)

\subsection{Elements of performance management}

Primary elements of PMS include mutual agreement, measurement of performance, feedback and comments, reinforcement that could be positive or negative and two-way discussion (Armstrong M. , 2006).

\subsection{Autonomy of performance}

There are certain issues with PMS in the Designing and its implementation, managers focus, alignment with strategic goals, consequences of performance management results, manager's skills, new pressures while performing, poor implementation of the system and poorly defined autonomy(Armstrong M. , 2006).

\subsection{Essence of performance management system}

An organization could gain competitive advantage by performance management system as it improves capabilities of employees by effectively not only managing them but developing them too (Cabrera and Banache, 1999). 


\section{MInstitute Macrothink $^{\text {Int }}$}

\subsection{Significance of PMS}

(Lingle, 1996)(Schiemann, 1996)Hoque and James, 2000) (Davis, 2004) and (Bititci, 2006) suggested that those institutions that use systematic, integrated and documented performance measures can perform better.

\subsection{Objectives of Performance Management System}

Performance management aims these points:

It clarifies goals, mission, job responsibilities, Priorities and supervisor's expectations.

It increases two way communication and participation.

It identifies actual and desired performance gaps and resolves them.

It recognizes quality performance and aligning it with organizational goals and strategies.

Provision of administrative decisions grounds such as promotion, demotion, succession planning and pay.

The main aim of performance management is to convert the unpolished capabilities of the employees of the organization into performance by eliminating the obstacles in between them, along with revitalization and the encouragement of the employees (Kandula, 2006).

Aguinis (2007) states that performance management is an ongoing practice of recognizing, estimation and the progression of the employees on how well they perform in an organization. Further stating that this development of the employees needs to be done with clearly identified objectives in the mind of the organization, with constant measurement of performance and they also require frequent feedbacks. The main aim of performance management is to improve the abilities of the personnel. Managers tend to identify frequent changes and react to them through performance management (Cokins, 2004).

\subsection{Purposes of PMS}

Information collected from performance management can be used for making decisions like employee's feedback, recognizing strengths and weaknesses of employees, salary adjustments decisions, promotion, demotion, transfer, firing, developmental areas, training and documentation in case of litigation. (Aguinis,2007)

\subsection{Key areas of PMS}

Strategy: Creating a link between an organizational strategy and an individual performance.

Evaluation: Actual and desired performance in accordance with the goals.

Development: Career advancements, needs and capabilities of an individual.

Diagnosis: Performance problems(Aguinis, 2007)

\subsection{Features of true PMS}

An ideal performance management system must include following characteristics to achieve 
positive outcomes.

Agreement between subordinates and supervisors on what performance is needed. What needs to be done without any doubt and how it needs to be done? It provides a clear guidance to the performance of individuals (Lawler, 2008). It guides the development of individuals so that they can use their skills and knowledge to perform effectively and they can enhance their skills and knowledge through trainings (Boland \& Fowler, 2000)

it motivates individuals to perform at a high level as the training will be provided. It needs to provide data about how individuals are performing, and what skills and knowledge exist in the organization, and their future needs. This information plays a vital role to the talent management as well as strategic planning (Lawler, 2008)

Aligned with Strategic goals: Performance goals should be congruent with strategic goals

Practical: PMS should be realistic and achievable. It shouldn't be too expensive nor time consuming with regards to the benefits.

Significant: PMS system should be meaningful and influential according to the needs of the organization.

Specific: PMS should be focused towards the targets. It should provide a clear guidance to the employees about what and how to be achieved.

Distinguish effective and ineffective performance: System should provide all the necessary information from all the sources that allow managers to differentiate between effective and ineffective performance.

Reliable: System should be reliable and must provide true results. Measures of performance should be error free and frequent and consistent.

Valid: System should accurately measure what should be measured exactly. It should provide all the relevant information.

Acceptable: The system should be fair enough to be accepted by all participants.

Thorough: PMS should be detailed and comprehensive should include all the phases properly and well managed.

Standardized: Performance should be evaluated frequently and consistently with a standardized procedure and measures. It should provide equal opportunities to all participants.

Openness: There shouldn't be any hidden or secretive methods or system used that reduces or overlap employee's performance.

Ethical: PMS should comply with all ethical standards and should respect the privacy of the employees

Correct: Standards and measures use should be correct and accurate. It should provide fair ratings that cannot be challenged legally. 


\section{Macrothink}

International Journal of Human Resource Studies

ISSN 2162-3058

2016, Vol. 6, No. 1

Inclusive: PMS should be including all the employees in the processes and should represent concerns of all employees. (Anguinis,2007)

\subsection{Positive contributions of PMS}

By the virtue of performance management system we can get positive outcomes:

Clarifies organizational goals, mission and vision to employees

Manager gain knowledge and information about subordinates

Job description, criteria and job definition get clear for employees

Differentiation among high, low and average performers

Protection from law suits

Supervisors expectations about performance is well communicated

Motivation level of employees increases

Change can be better managed

Self-efficacy increases

Self-monitoring, actions and performance get more appropriate

Self-knowledge and development is enhanced

Competency and talent is promoted(Aguinis,2007)

\subsection{Performance management system process}

Performance management process plays a vital role in identifying whether an organization is managing its Human Resource effectively and efficiently or not. It provides information about which employee needs training and development and which employee needs to be appraised and rewarded. It starts with the planning and ends with giving feedback to the employees. Performance management process should guide a goal setting process, it should lead towards individuals team and business objectives linked with strategic goals, it should become from top to down, there should be a mutual agreement on what and how it should be achieved (Greenberg, 1986).Performance Management is the process in which objectives are clearly defined and individual targets and team's goals are set mutually and the regular review of the variance between actual achievement and desired goals is focused and ultimately rewards are linked with the goal achievement. Performance management helps in identification of training need analysis and developmental needs of the employees. In the absence of performance management system it is impossible to get the primary information or data that gives the clear view of the areas that needs the training the most and organization will be unable to use its training resources efficiently. (Aguinis, 2007)

Performance management process is all about performance it includes:

Planning Performance: setting Key Performance Area's (KPA's), objectives and standards that 
are linked to corporate strategy, development plans

Maintaining Performance: monitoring, feedback, coaching and mentoring and regular interactions and two way discussions regarding goal achievement

Reviewing Performance: formal feedback and ratings and evaluating performance

Rewarding of Performance: increases, bonuses, incentives, promotions and recognition

Performance management is about developing an integrated and holistic framework. Performance management encompasses vast extents that give strength to each other to get maximum outcome for an organization. The main focus of previous case study was a bank office, where a personalized performance management framework was developed to make a harmonized and team work environment (Bjørn Andersen, 2006).

\subsection{Performance planning}

Performance management system starts with planning. It's the prerequisite of performance management system. Performance planning is communicating setting clear and specific goals and establishing priorities. Throughout the Planning phase, the immediate boss and employee with mutual understanding decides what was expected in terms of the Accountabilities and Behaviors. Performance planning is in congruent with overall business strategies according to the job description and each employee's performance should be linked with overall business Performance driven by business strategy and mutually set goals make a positive contribution to performance management system (Armstrong, 2006).Performance planning defines Key Performance Areas (KPA's), Objectives and Targets. The main aspect of any good performance management system is training and development. Part of the planning phase includes the agreement on a formal development plan for the employee in terms of competency, skills and behaviors. That will be required to perform the already set goals. Training should be based upon performance gaps or variations so that the gap can be filled. These gaps are easily identified by maintaining and reviewing the performance. Performance management also provides key information for employees planning and succession planning. Particularly, an organizations' talent stock or talent management information is gathered through the performance management system. Developmental plans that keeps the organization well informed about the current skills and talents of employees and future needs of the nature of tasks this information is also used in recruitment and selection process as it gives the clear idea of what is needed further and what skills we have already. Which skills and knowledge we need externally or got to outsource and what type of skills are readily available within organization. (Aguinis, 2007).Developmental plans can be planned according to the needs of the employees. Developmental plans can be long term initiatives. It can be based on high performance. Performance review and evaluation will provide an input data that helps in analyzing training needs. Training and development along with performance management process should be aligned with overall business strategy. Training and development interventions are an important factor for skill retention in an organization. (Teke, March2002). Performance management system process should be started from mutually coordinated goals and organizational strategies (Greenberg, 1986) . Performance 
appraisal that's part of performance management should be aligned with organizational goals having objectives that can be measured(Latham, 1990)

\subsection{Performance expectations}

Defining targets, standards and expected outcomes. Discussion with employees about what a manager wants from his employee (Kloot\& Martin , 2000). What should be done and how goals should be achieved. An organization can convey supervisor's expectation, through goal achievement and improved quality an organization can increase its employees' confidence and their job satisfaction (Locke, 1984).

\subsection{Performance criteria}

It's about Informing employees about basis of performance, job description and basis of progress monitoring. It's like a yardstick to measure performance or benchmark to compare performance against. Performance standards or criterion is how an employee will perform the task adding the standards to the accountabilities will help the supervisor in justifying the performance review questions asked by employee's performance standards clarify the ways how a supervisor can measure whether objectives have been met effectively or not how well task have been performed. Performance standards must include: Quality: It refers to an accuracy of the task; how well the task is being performed error rate or percentage can be mentioned. Like $2 \%$ rejection is allowed. Next characteristic of standard is quantity (Otley, 1999): That is how much results should be produced or how many outcomes units should be accepted for example 200 units per hour. Time: it includes within how much time or duration or how fast a task should be done like within 3 hours or within three rings a call must be received. Manner: In which style or manner a task must be performed means one need to be courteous, friendly while answering public calls. Method: which method should be used to perform a task which procedure, policy or consideration to be kept in mind or should be followed while performing a task for example all the forms must be filled. Cost: It includes the budget and effective way to carry out a task less input and more output by effective use of human resources.

Effectiveness and criterion or measures how individuals perform their tasks are highly dependent. PMS perform well when employees are evaluated on both their results and how to achieve them. (Armstrong, 2006).Performance appraisal system was previously based on personality traits and immeasurable objectives, and the criterion was not well-defined then it moved towards job description and proper job related measureable outcomes. The performance management system need to be based on goals aligned with strategic goals and whose achievement is measurable (Locke and Latham,1990).

\subsection{Implementation}

It includes executing the planned performance and improvement programs. It is the longest phase of PMS and it is also a big challenge for the management. Organization would suffer from a lot of negative consequences if the PMS system is not implemented properly.

There comes a lot of problems encountered during the implementation and use of a 
performance management system (PMS).Different studies showed that the success rate of PM implementations has increased in the past decade from 30 to 44 percent, and that the problems identified in the organizations are: lack of executive commitment; no PM culture; no priority to pm system, low attention towards its implementation and employees are not much benefited from PMS (André A. de Waal, 2009).Poor implementation of Performance management system can bring up number of issues:

Turnover: Employees may leave the organization due to unfair results. They may get upset and reduce level of efforts (Pollitte, 2005).

Decreased Self-efficacy: Employee's self-confidence and self-esteem may decrease if the feedback is destructive and discouraging.

Wastage of Money: PMS system cost budget and all the funds will be wasted if the end product is negative.

Misleading Information: When the process of PMS is inappropriate then false and wrong information will bring up wrong decisions about employees performance.

Relationships are broken: Relationships between employees and supervisors are damaged due to lack of trust in the system.

Wastage of time: Time to plan and implement the PMS process will be wasted as the results will not be satisfactory. Decreased motivation: Motivation to perform a task or work will be reduced due to improper PMS process. Irrational demands: Unjustified demands of other employees about promotions and incentives will be increased.

Biases: Biases and prejudices will be highlighted. Law suits: Decisions can be challenged legally (Aguinis,2007).

\subsection{Ongoing coaching and multiple sources of feedback}

Discussions about improvement areas and programs focused towards excellence, learning and identifying performance boundaries. Coaching is a formal process of skill transfer, guidance and feedback. It helps employees to recognize the opportunity and importance to improve. Coaching allows the supervisor the chance to motivate the employee's development. Coaching takes place throughout the year. It is an interactive process. Information taken from peers, customers and clients about the behavior of employee to ensure the targets is achieved properly. Plans and leads meetings to ensure that issues are discussed and agendas are met and providing others employees with timely and accurate feedback. Immediate boss should Identifies and removes obstacles that may get in the way of good performance Supervisor should ask for others' opinions, ideas and recommendations to involve others in improving the work situation (Modell, 2001).

Feedback plays an important role in employee's morale and motivation. Feedback should be positive, constructive based on facts and figures with documented evidences. Feedback is a two-way communication that helps employee in identifying and improving the areas where he lack and couldn't perform well. Discussion should be encouraging and focused towards 
positivity and aimed at improvement. Regular performance feedback is an important factor in skill retention in an organization (Teke, March2002).

Continuous feedback by supervisors is directly related to performance effectiveness. Results by researchers also suggest building continuous feedback into their performance management system. (Armstrong, 2006)

A detailed and constructive performance feedback system increases organizational learning and development and an organizational strategy must include feedback on good performance. (Milton Mayfield, 2012).

\subsection{Performance review and evaluation}

Documents and meetings focused towards progress, development, improvements and areas of excellence about staff performance. Research shows that individuals are very fidget before and during the performance reviews and evaluation (Culbert, 2010). Performance of employees is reviewed according to the already set goals. It resolves all the problems with performance and keeps it moving ahead directed towards strategic planning. Appraisal is an ongoing process of evaluation and reviewing it's a formal written exercise that held twice or once in a year. It's now changed now from paper work to continuous exercise.(Armstrong M. a., 2005).Performance appraisal emphasizes the evaluation of an employee's strengths and weaknesses.

Evaluation of performance is very necessary in order to differentiate between high performance and ineffective performance. Through evaluations performance problems can be recognized or diagnosed. Evaluation is important to identify the performance deviations from already set standards employees and to set their performance back on track in accordance with organizational goals. The study of the performance management systems of public healthcare system showed that the accountability was poor, no vertical control between PHSs and parent organization, lack of direction and hence less motivation to perform tasks It is found that the performance (Paulino Silva, 2010).

The employee performance can be measured by different criteria or methods (West, 2004)

Performance of an employee is evaluated on the basis of different characteristics and various sources like customers, peers and subordinates often give useful information (Bohlander, 2009). Performance review data can be demonstrated in diagrams that help the team move rapidly through the quality process like performance against benchmark or target data and measures.

\subsection{The evaluation team}

Supervisor will appraise his subordinate without any biasness on the basis of facts and figures. Evaluation can be positive, negative and neutral. One should not be biased or inclined while evaluating a subordinate it should be fair evaluation. While designing such system the question of main concern is that who will evaluate or judge employees' performance so the answer to this question most of the time is that immediate boss or supervisor will appraise the subordinate (Murphy, 1995) 


\subsection{Evaluate Outcomes but Don't Rank}

In the establishment of a performance appraisal process the first step is, setting goals focus towards development, but that is how the process starts. An effective evaluation is that how well the goals are accomplished. It should be understandable by everyone and it should be a management by agreement. The right measurement approach should be used. Some organizations do not evaluate outcomes but they rank it. Ranking creates misleading data, it conveys a message that organizations do not value its talent, and they are not showing any concern for individuals and are not inclined towards fairness in the evaluation process. Seriously flawed rating practice is, forced distribution (Lawler, The Folly of Forced Ranking, 2002). Some organizations want their managers to make a certain percentage of their employees that fall from 5-10\% not performing well. A certain parentages like 15-20 of those who are performing well. This type of performance appraisal methodology neglects the reality that some work teams have no poor performers and have no good performers. These types of rating methodologies cause employees to deny the existence of appraisal outcomes. They are more towards following the rules, and are forced to give some employees a low rating. This causes a serious havoc when rewards are attached with different areas of the distribution. Various studies showed that this kind of practice results in a political behavior on the part of individuals forming in the organization (Lawler, Making people your competitive advantage, 2008).

\subsection{Frequency of evaluation}

Frequency of the performance management system decides whether the system is training and development oriented or inclined towards quantitative issues like administrative decisions promotions, rewards and reinforcement. Supervisors need to be aware of all the biases that occur while evaluating an employee. The main aim of the performance management system depends upon the frequency of the frequency of the performance appraisal. If it is conducted within a short interval it means the main purpose of the PMS is development, training and on quantitative factors. The accuracy, employee satisfaction and apparent justice all these factors depend upon the frequency of evaluation (Werner, 1997). Evaluation should be transparent and fair enough to be trusted backed by facts and figures.

\subsection{Performance management system and reward management system}

Rewards are usually referred to as tangible returns that include cash compensation (i.e., base pay in exchange of work perform, cost of living and merit pay to combat inflation, it can be short and long term incentives allocated on past performances, and benefits (i.e., income protection, work/life focus, tuition reimbursement and allowances covering housing and transportation) Though, some employees also receive intangible returns or we can say relational returns, which include recognition and status like employee of the week, employment safety, thought-provoking work and education opportunities. A reward system is the establishment of tools for issuing both tangible and intangible returns as measure of an employment affiliation. It should be noted that not all types of returns are directly related to performance management systems but mostly rewards are directly related to the high performance. (Aguinis, 2007).High performance should be reinforced by management. High 
performers should be encouraged and promoted. Effective performance should be rewarded. There is a noticeable association between performance management and reward system. Compensation and reward judgments are likely to be illogical without a good performance management system (Aguinis, 2007)

Rewards system plays an important role in increase performance of employees and in bringing up behavioral changes in unsatisfied employees. As positive reinforcement will motivate employees and boost their morale. Furthermore it will increase performance efficiency and effectiveness. Effectiveness will be higher when performance is linked with rewards (Armstrong, 2006)

According to Brian K. Boyd and Alain Salamin(Aug., 2001), Rewards given to employees by an organization is directly proportional to the performance, recruitment and employee's retention.

According to (Mujtaba) and Bahaudin, Reward system should be linked with organizational strategy, employee's performance, employee's development and it should promote talent. This will empower the high performing employees and motivate them to perform better as it will reinforce their positive behavior.

\section{Research Methodology}

The research study is descriptive in nature and hence requires the following appropriate methodology for accomplishing the given set objectives.

\subsection{Data Collection}

The research data of this study will be collected with the help of structured questionnaires to be filled from the Officers engaged in evaluating the performance of the employees working at Branch and Regional level in Bahawalpur Region of Pakistan.

\subsection{Sample}

A sample of 100 respondents have been selected on convenience keeping in view the available managerial positions and the personnel available in the Bahawalpur Region of Pakistan, however, the Bahawalpur region will cover district Rahim Yar Khan , Lodhran, KehrorPacca, Hasilpur and Bahawalpur.

\subsection{Data Analysis}

The statistical techniques of Chiq-Squre, Frequency Distribution, Standard Deviation and Mean will be applied to arrive on the numerically computed responses of the questionnaire collected from the target respondents. Preferable help will be taken from the Statistical Software to arrive on results for interpretation and analysis.

\subsection{Primary Data}

The interviews from the key personnel seating in Bahawalpur Region of Pakistan will be conducted to support the theoretical model of the study derived from the literature and support of the responses of the target respondents. 


\section{Macrothink}

\section{Findings}

- Bell Curve system/technique is used in performance management system.

- No proper feedback regarding employee's performance.

- Employees' performance weaknesses and strengths are not discussed openly with employees.

- There's an annual performance appraisal system.

- Motivation level of employees regarding performance management system of National Bank is low.

- Performance criterion is set without mutual consent.

- Performance Objectives are not mutually discussed and agreed upon.

- Participation level of employees in performance management system is very low.

- Performance appraisal is done by immediate supervisor.

- Employees are rewarded according to the performance appraisal.

- Supervisors are sometimes biased as the performance appraisal is only done by immediate boss.

\section{Conclusion}

Performance management plays a significant role as it clarifies job responsibilities, priorities and expectation. Participation of employees in PMS and feedback is very critical in motivating employees to perform effectively and efficiently towards goals achievement.

\subsection{Recommendations}

- Need based training system should be introduced. Trainings should be imparted when there is a need of a particular skill.

- Training should be imparted according to skill level and temperament of employees.

- Appraisal system should be changed according to the need of the hour. All the employees should be rated according to their performance against the agreed upon job objectives.

- There should be proper feedback of the appraisal. Employees should be told why they have been given a particular grade. This will increase the satisfaction level of the employees.

- Job Objectives should be set after detailed discussions with the employees.

- Education of the employees should be improved through different courses and workshops and they must be given opportunity to take admissions in educational institutions. 
- Quarterly performance development discussions should be made.

\section{References}

Aguinis, H. (2007). Performance management. London: Prentice Hall

André A. de Waal, H. C. (2009). "Lessons learned from performance management systems implementations". International Journal of Productivity and Performance Management, Vol.58 No.4 pp. 367-390

Armstrong, M. (2006). Performance Management: Key Strategies and Practical Guidelines (3 ed.). Kogan Page.

Armstrong, M. A. (2005). Managing Performance: performance management in action. London: CIPD.

Bititci, U. M. (2006), "Dynamics of performance measurement and organisational culture", International Journal of Operations and Production management, Vol. 26 No.12, pp.1325-1350.

Bjørn Andersen, B. H. (2006), "Holistic performance management: an integrated framework" International Journal of Productivity and Performance Management, Vol. 55 No. 1 pp. 61 78.

Bohlander, G. A. (2009). Managing Human Resources. South Western: Thompson.

Boland T. \& Fowler A., (2000), "A System Perspective of Performance Management in Public Sector Organizations" The International Journal of Public Sector Management" Vol. 13 No. 5, pp. 417-446

Brumbach, G. B. (1988). Some ideas, issues and predictions about performance management, Public Personnel Management, Winter.

Cokins, G. (2004). Performance management: Finding the missing pieces and closing the intelligence gap. Australia: John.

Culbert. (2010), "Get rid of the performance reviews: How companies can stop intimidating, Start managing and focus on what really matters", New York Business Plus.

Davis, S. A. (2004). "An investigation of the effect of balanced scorecard implementation in financial performance“. Management Accounting Research, Vol. 15 No. 2, pp. 135-153.

Greenberg J., (1986), "Determinants of Perceived Fairness of Performance Evaluation", Journal of Applied Psychology, Vol. 71 No. 2, pp. 340-342

Kandula, S. R. (2006). Performance Management. New Delhi: Prentice Hall of India Private Limited.

Kloot L. \& Martin J. (2000), "Strategic Performance Management: A Balance Approach to Performance Management Issues in Local Government", Management Accounting Research, 
Vol. 11, pp. 231-251

Latham, E. A. (1990). A Theory of Goal-Setting and Performance. Englewood Cliffs, N.J.: Prentice Hall, Wiley and Sons.

Lawler. (2002), “The Folly of Forced Ranking.” Strategy+ Business, Vol. 28, pp. 28-32.

Lawler. (2008). “Making people your competitive advantage.” San Francisco Jossey-Bass.

Lingle, J. A. (1996). "From balanced scorecard to strategic gauges: is measurement worth it?" Management Review, Vol. 8 No. 3, pp. 56-76.

Locke, E. a. (1984). Goal Setting: A motivational technique that works! London: Prentice Hall International.

Michael Armstrong, A. (1998). Performance Management: The New Realities, Institute of Personnel and Development. London.

Milton Mayfield, J. M. (2012). "Effective performance feedback for learning in organizations and organizational learning." Development and Learning in Organizations, Vol.26 No.1, pp. $15-18$.

Modell S., (2001), "Performance Management and Institutional Processes: A Managerial responses to Public Sector reforms" Management Accounting Research, Vol. 12, pp. 434-464

Mujtaba, B. G. (n.d.). Coaching and Performance management: developing and inspiring leaders.

Murphy, K. R. (1995). Understanding Performance Appraisal: Social, Organisational, and Goal-Based Perspectives. Thousand Oaks CA: Sage.Wall, Toby D., Jonathan Michie, Malcolm Patterson, Stephen J. Wood, Maura Sheehan, Chris.

Otley D., (1999), "Performance Management: A Framework for Management Control Systems Research”, Management Accounting Research, Vol. 10, pp. 363-382

Paulino Silva, A. F. (2010). "Performance management in primary healthcare services: evidence from a field study." Qualitative Research in Accounting \&Management, Vol. 7 No.4, pp. 424 - 449.

Pollitte C., (2005), "Performance Management in Practice: A Comparative Study of Executive Agencies", Journal of Public Administration Research \& Theory, pp. 1-20

Teke, M. (March2002). Retention strategy. HR future, 10-12.

Walters, M. (1995). The Performance Management Handbook, Institute of Personnel and Development. London.

Werner, J. M. (1997). "Explaining U.S. Courts of Appeals Decisions InvolvingPerformance Appraisal: Accuracy, Fainess and Validation.” Personnel Psychology, Vol. 50 No. 1, pp. 1-24.

West, W. A. (2004). "On the Validity of Subjective Measures of Company." Personnel Psychology, Vol. 57 No.1, pp. 95-118 